\title{
EFFICIENCY OF USING THE DIODE LASER IN THE TREATMENT OF PERIODONTAL INFLAMMATORY DISEASES
}

DOI: 10.36740/WLek202005101

\author{
Nataliia G. Gadzhula, Mariia M. Shinkaruk-Dykovytska, Olena L. Cherepakha, Maryna A. Goray, Irina M. Horlenko
}

NATIONAL PIROGOV MEMORIAL MEDICAL UNIVERSITY, VINNYTSIA, UKRAINE

\begin{abstract}
The aim: To study clinical efficiency of using the diode laser in the treatment of chronic catarrhal and hypertrophic gingivitis.

Materials and methods: Treatment of 32 patients with chronic catarrhal gingivitis and 30 patients with hypertrophic gingivitis by basic therapy according to the protocols of dental care was carried out. The patients of the main groups were additionally subjected to laser irradiation of the affected areas of the gums with a diode laser.

Results: The use of laser therapy in the treatment of chronic catarrhal gingivitis contributed to the pain relief, reducing of bleeding and edema of the gums in $68.8 \%$ of patients on the 3rd day of observation. On the 7th day, $93.8 \%$ of the examined patients had no inflammation in periodontal tissues. During treatment of hypertrophic gingivitis, antiinflammatory and decongestant effects, improvements in the aesthetic appearance of the gums were revealed in $33.3 \%$ patients on the 3rd day of the examination; absence of inflammation, gingival bleeding and gum hypertrophy was diagnosed in $53.3 \%$ on the 7 th day and in $80.0 \%$ patients on 14 th day of follow-up. In the control group, similar changes were revealed only in $68.8 \%$ patients with catarrhal gingivitis and in $46.7 \%$ patients with hypertrophic gingivitis after complete course of drug treatment in 14 days of observation.

Conclusions: The use of a diode laser in patients with chronic gingivitis has provided a reduction in the term required for the complete elimination of the inflammatory process and suspended its further progression.
\end{abstract}

KEY WORDS: catarrhal gingivitis, gingival enlargement, diode laser, gingival bleeding index, oral hygiene index

Wiad Lek. 2020;73(5):841-845

\section{INTRODUCTION}

Periodontal diseases are a significant medical and social problem, due to their tendency to chronization, persistent course and progression. The high prevalence of inflammatory periodontal diseases is associated with poor oral hygiene, untimely treatment by a dentist and lack of prophylaxis [1]. In the absence of an effective treatment for chronic gingivitis, there is an increased risk of generalized periodontitis development, this leads not only to the rapid loss of a significant number of teeth, but also affects the overall health and quality of life [1-2]. Correlation between general body condition and periodontal changes is complex. The affected tissues that make up the periodontium, capable of creating a pathogenic effect on the body, complicate the disease course and cause the development of the chronic septic state of the body [3].

That is why gingivitis treatment is an important task of theoretical and practical dentistry and requires the use of the modern methods of treatment. The introduction of laser systems in dental practice opens up new opportunities in the development of methods of minimally invasive, accelerated and effective treatment of periodontal diseases, which can reduce treatment time and contribute to the long-term stabilization of the inflammatory process [4-7].

\section{THE AIM}

The aim of the research was to study the clinical effectiveness of using a diode laser in the treatment of catarrhal and hypertrophic gingivitis.

\section{MATERIALS AND METHODS}

32 patients with chronic catarrhal gingivitis and 30 patients with granulation (edematous) form of hypertrophic gingivitis of I degree of various prevalence were treated. There were $27(43.54 \pm 9.54 \%)$ men and 35 (56.45 $\pm 8.38 \%)$ women aged 17 to 35 without somatic pathology among them. They have gingivitis associated with dental plaque only (Plaque-Induced Gingival Diseases). While clarifying the anamnesis vitae, patients denied the presence of somatic diseases. Diagnosis was confirmed according to the classification of periodontal diseases by N. F. Danilevskiy (1994) and G. F. Biloklytska additions (2007) [1].

Patients of each nosological group by random sampling were divided into the main and control groups, equal in number and gender. Patients of all groups underwent a complex of medical and prophylactic measures, which included professional oral hygiene, training in teeth brushing, and complete sanitation of oral cavity with subsequent treatment of gingivitis in accordance with medical care protocol [8]. Patients of the main groups were additionally 
treated with non-contact laser irradiation of the affected gingival areas with a Picasso diode laser ("AMD Lasers", USA) with a wavelength of $940 \pm 15 \mathrm{~nm}$ in constant mode with a power range of $0.5 \mathrm{~W} / \mathrm{cm}^{2}$ when using non-activated fiber "Program 4". Exposure - 2 minutes on each zone, number -3 procedures daily for catarrhal gingivitis and 6 procedures for hypertrophic gingivitis (Fig. 1-2).

Efficiency assessment was carried out on the 3rd, 7th and 14th day from the start of treatment based on subjective data, the results of an objective examination, as well as the dynamics of indicators for the index assessment of the oral cavity state. During the clinical examination were evaluated: color, size, shape, consistency, surface texture, contour of the gingiva, the presence of edema and bleeding. The hygiene index was calculated according to Simplified Oral Hygiene Index by J. C. Greene and J. R. Vermillion (OHI-S, 1964). The state of periodontal tissues was objectified based on the analysis of the Papillary-Marginal-Attachment Index (PMA) in the modification by C. Parma (1960) and the Papillary Bleeding Index (PBI) according to H. R. Muhlemann (1977). In order to eliminate symptomatic gingivitis at generalized periodontitis, the $\mathrm{X}$-ray examination was performed.

The analysis of statistical data was performed using the method of the Student parametric criterion according to the principle of variation statistics. Values of $p<0.05$ were considered statistically significant.

All research methods and experiments have been examined and approved by the appropriate ethics committee and have therefore been performed in accordance with the ethical standards laid down in the Declaration of Helsinki.

\section{RESULTS}

During the initial examination, the complaints of patients with catarrhal gingivitis in the main and control groups were identical: of unpleasant sensations (discomfort) in the gums, itching, gingival bleeding when eating solid food and brushing teeth, bad breath. Congestive hyperemia with pronounced cyanosis of the gingival margin, swelling of the interdental gingival papillae, their friability and pastiness, pain during palpation, as well as a significant amount of soft plaque in the area of the teeth neck were objectively noted. The average values of papillary bleeding index (PBI) were $2.39 \pm 0.05$ scores in the main group and $2.24 \pm 0.07$ scores in the control group ( $\mathrm{p}>0.05)$. The PMA and OHI-S index values were significantly high $(33.31 \pm 3.13 \%$ and $1.53 \pm 0.17$ scores in the main group and $31.98 \pm 3.06 \%$ and $1.46 \pm 0.16$ scores in the control group), which indicated a high degree of gum inflammation and a low level of oral hygiene (Tables I-III).

Patients with a granulation form of hypertrophic gingivitis complained of gingival enlargement, itching, bleeding and tenderness of the gums, which increased while eating and brushing. During objective examination the edema and diffuse congestive hyperemia of the gums, enlargement of the interdental gingival papillae to $1 / 3$ of the height of tooth crown and the presence of gingival pockets were revealed (Fig. 3). PBI scores of $2.69 \pm 0.09$ in the main group and $2.65 \pm 0.18$ in the control group ( $\mathrm{p}<0.05)$; PMA $-46.41 \pm$ $2.79 \%$ and $45.98 \pm 3.06 \%$, respectively; OHI-S scores are significantly high $(1.93 \pm 0.15$ and $1.95 \pm 0.18, \mathrm{p}>0.05)$.

On the 3rd day from the beginning of the treatment of catarrhal gingivitis patients of the main group have already indicated an improvement of the gingiva state: the decrease in soreness and bleeding, an unpleasant odor from the oral cavity. An objective examination of $11 / 16(68.75 \pm 11.59 \%)$ patients with catarrhal gingivitis showed a decrease in gum edema (PMA $-15.16 \pm 2.93 \%$ ), the presence of slight papillae bleeding (PBI score of $1.43 \pm 0.10)$ and improved oral hygiene (OHI-S score of $0.60 \pm 0.15$ ).

In the three days from the start of hypertrophic gingivitis treatment, the gum state was improved: edema and bleeding of the gingival papillae were decreased, but the aesthetic defect and the phenomena of gums hypertrophy were remained. There was a decrease of PMA indexes to $24.16 \pm 2.93 \%$, PBI score to $1.58 \pm 0.12$, OHI-S score to $1.08 \pm 0.09$ with statistical significance $\mathrm{p}<0.001$.

On the 3rd day of the clinical examination the patients with chronic catarrhal gingivitis of the control group also indicated an improvement in the clinical manifestation of the disease: the decrease of discomfort, soreness and

Table I. Assessment of oral hygiene in the treatment of chronic gingivitis based on $\mathrm{OHI}-\mathrm{S}$ index, in scores

\begin{tabular}{|c|c|c|c|c|}
\hline \multirow{2}{*}{ Terms of observation } & \multicolumn{2}{|c|}{ Chronic catarrhal gingivitis } & \multicolumn{2}{|c|}{ Hypertrophic gingivitis, edematous form } \\
\hline & Main group $(n=16)$ & Control group $(n=16)$ & Main group $(n=15)$ & Control group $(n=15)$ \\
\hline \multirow{2}{*}{ Before treatment } & $1.53 \pm 0.17$ & $1.46 \pm 0.16$ & $1.93 \pm 0.15$ & $1.95 \pm 0.18$ \\
\hline & & $p_{1}>0.05$ & & $p_{1}>0.05$ \\
\hline \multirow{2}{*}{ 3rd day of treatment } & $0.60 \pm 0.15$ & $0.87 \pm 0.16$ & $1.08 \pm 0.09$ & $1.47 \pm 0.16$ \\
\hline & $p<0.001$ & $p<0.001 ; p_{1}>0.05$ & $\mathrm{p}<0.001$ & $\mathrm{p}<0.001 ; \mathrm{p}_{1}<0.05$ \\
\hline \multirow{2}{*}{7 th day of treatment } & $0.47 \pm 0.14$ & $0.88 \pm 0.12$ & $0.56 \pm 0.13$ & $0.94 \pm 0.13$ \\
\hline & $\mathrm{p}<0.001$ & $p<0.001 ; p_{1}<0.05$ & $\mathrm{p}<0.001$ & $\mathrm{p}<0.001 ; \mathrm{p}_{1}<0.05$ \\
\hline \multirow{2}{*}{ 14th day of treatment } & $0.43 \pm 0.13$ & $0.85 \pm 0.13$ & $0.53 \pm 0.12$ & $0.87 \pm 0.11$ \\
\hline & $p<0.001$ & $\mathrm{p}<0.001 ; \mathrm{p}_{1}<0.05$ & $p<0.001$ & $\mathrm{p}<0.001 ; \mathrm{p}_{1}<0.05$ \\
\hline
\end{tabular}

Note: $p$ - the significance of the difference between the index values before and during treatment ( $3 r d, 7$ th, 14 th day); $p_{1}-$ the significance of the difference between the indexes of the main and control groups. 


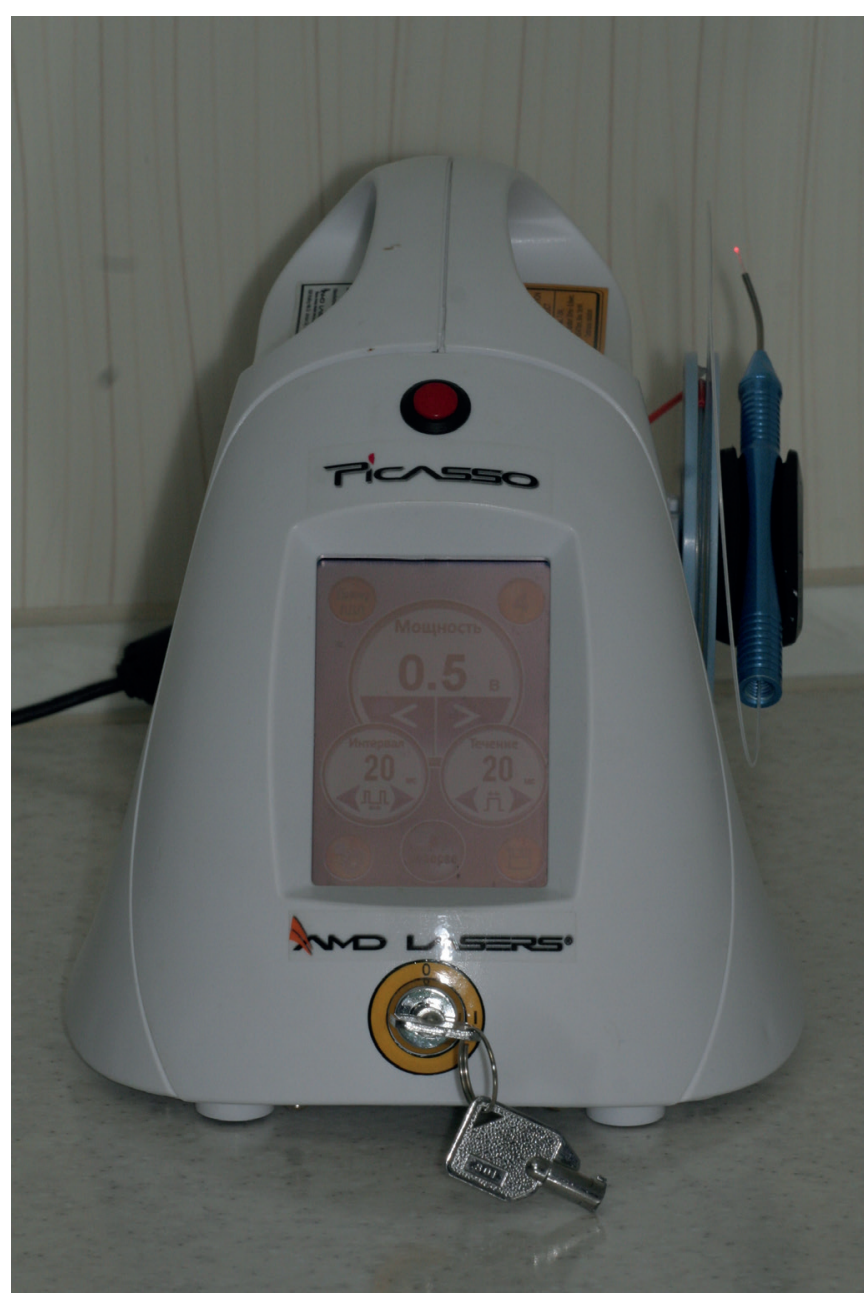

Fig. 1. Picasso diode laser ("AMD Lasers", USA).

bleeding of the gums. An improvement in the oral cavity hygiene was noted: the average values in OHI-S index were significantly $(\mathrm{p}<0.001)$ lower than the initial values. However, no significant changes in the improvement of PMA and PBI indexes were observed ( $p>0.05)$. An objective examination of the patients with hypertrophic gingivitis in the control group showed no improvement in the gingiva state: gingival hypertrophy remained, and the decrease of the PMA and PBI indexes was unreliable ( $p>0.05)$.

On the seventh day of observation, patients of the main group who were diagnosed with catarrhal gingivitis noted a lack of painful sensation, halitosis, and decreasing of gum bleeding. An objective examination showed no signs of gum inflammation, which was also confirmed by PBI scores of $0.68 \pm 0.12$ and PMA of $7.11 \pm 1.35 \%(p<0.001)$. The tendency of a significant decrease in Green-Vermillion index $(0.47 \pm 0.14$ scores, $\mathrm{p}<0.001)$ was revealed. In the group of patients with hypertrophic gingivitis the gingival margin form due to reduction of the edema was reestablished and disappearance of gum hypertrophy was observed in $8 / 15(53.33 \pm 12.88 \%)$ people. PMA index was $11.09 \pm 2.35 \%$, PBI score of $0.96 \pm 0.13\left(\mathrm{p}<0.001, \mathrm{p}_{1}<0.01\right)$.

Patients of the control group on the 7th day of the basic treatment indicated the decrease in soreness and bleeding of the gums when eating and teeth brushing, the absence

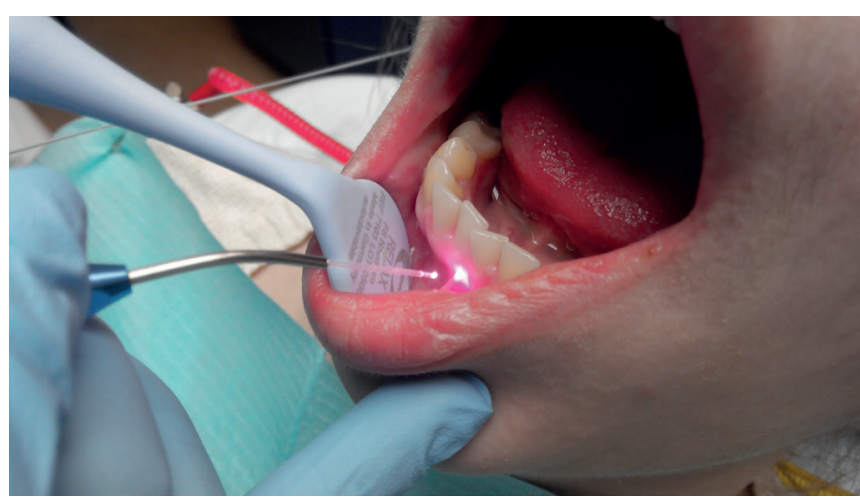

Fig. 2. The technique of carry out the laser therapy.

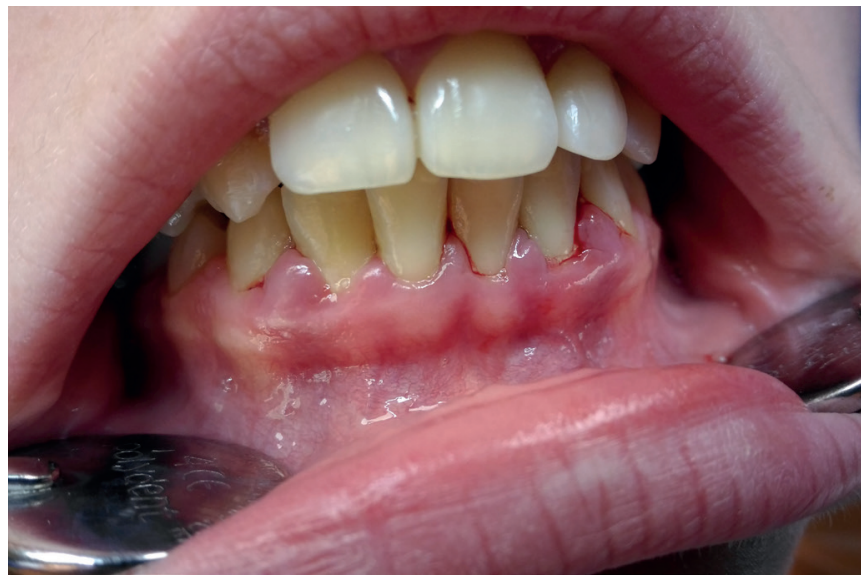

Fig. 3. Hypertrophic gingivitis, edematous form in the patient M., aged 23-years-old, of the main group at initial examination.

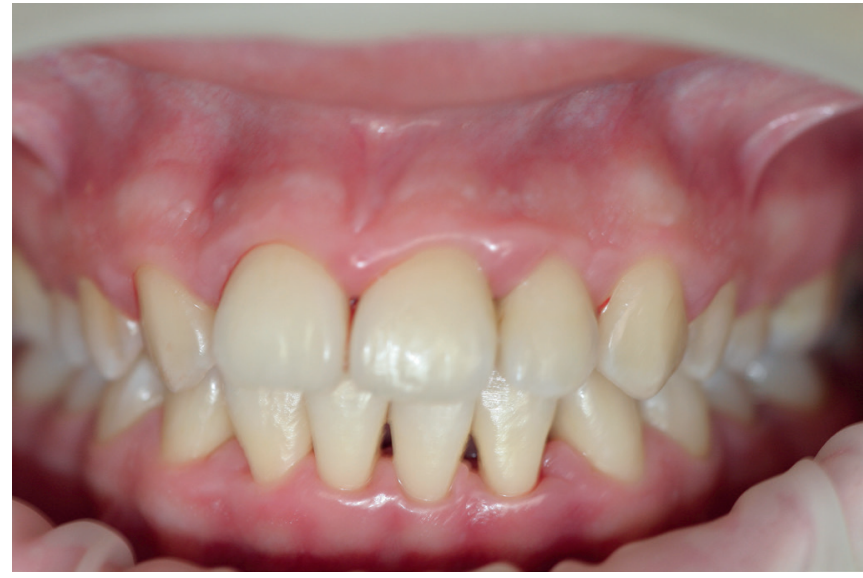

Fig. 4. Hypertrophic gingivitis, edematous form in the patient M., aged 23-years-old, in a week from the beginning of treatment with a diode laser.

of bad breath. An objective examination of $68.75 \pm 11.58 \%$ patients with catarrhal gingivitis showed improvement of the gingiva state: the disappearance of gum bleeding, swelling, and a pale pink color of the oral mucosa. However, there were signs of slight inflammation in the form of inconspicuous hyperemia, edema and pain, the presence of linear-point bleeding in $31.25 \pm 11.59 \%$ of individuals of this group. According to PMA index, the prevalence of low 
Table II. Assessment of periodontal tissues in the treatment of chronic gingivitis based on PMA index, in per cent

\begin{tabular}{|c|c|c|c|c|}
\hline \multirow{2}{*}{ Terms of observation } & \multicolumn{2}{|c|}{ Chronic catarrhal gingivitis } & \multicolumn{2}{|c|}{ Hypertrophic gingivitis, edematous form } \\
\hline & Main group $(n=16)$ & Control group $(n=16)$ & Main group $(n=15)$ & Control group $(n=15)$ \\
\hline \multirow{2}{*}{ Before treatment } & $33.31 \pm 3.13$ & $31.98 \pm 3.06$ & $46.41 \pm 2.79$ & $45.98 \pm 3.06$ \\
\hline & & $p_{1}>0.05$ & & $p_{1}>0.05$ \\
\hline \multirow{2}{*}{ 3rd day of treatment } & $15.16 \pm 2.93$ & $24.11 \pm 3.01$ & $24.16 \pm 2.93$ & $37.01 \pm 3.01$ \\
\hline & $\mathrm{p}<0.001$ & $\mathrm{p}>0.05 ; \mathrm{p}_{1}<0.05$ & $\mathrm{p}<0.001$ & $p>0.05 ; p_{1}<0.05$ \\
\hline \multirow{2}{*}{ 7th day of treatment } & $7.11 \pm 1.35$ & $14.02 \pm 2.18$ & $11.09 \pm 2.35$ & $22.02 \pm 2.18$ \\
\hline & $\mathrm{p}<0.001$ & $\mathrm{p}<0.05 ; \mathrm{p}_{1}<0.01$ & $\mathrm{p}<0.001$ & $p<0.001 ; p_{1}<0.01$ \\
\hline \multirow{2}{*}{ 14th day of treatment } & $2.80 \pm 0.78$ & $10.53 \pm 1.82$ & $5.80 \pm 1.78$ & $16.53 \pm 1.82$ \\
\hline & $\mathrm{p}<0.001$ & $p<0.05 ; p_{1}<0.001$ & $\mathrm{p}<0.001$ & $\mathrm{p}, \mathrm{p}_{1}<0.001$ \\
\hline
\end{tabular}

Note: $p$ - the significance of the difference between the index values before and during treatment ( $3 r d, 7 t h, 14$ th day); $p_{1}-$ the significance of the difference between the indexes of the main and control groups.

Table III. Assessment of periodontal tissues in the treatment of chronic catarrhal gingivitis based on the PBI index, in scores

\begin{tabular}{|c|c|c|c|c|}
\hline \multirow{2}{*}{ Terms of observation } & \multicolumn{2}{|c|}{ Chronic catarrhal gingivitis } & \multicolumn{2}{|c|}{ Hypertrophic gingivitis, edematous form } \\
\hline & Main group $(n=16)$ & Control group $(n=16)$ & Main group $(n=15)$ & Control group $(n=15)$ \\
\hline \multirow{2}{*}{ Before treatment } & $2.39 \pm 0.05$ & $2.24 \pm 0.07$ & $2.69 \pm 0.09$ & $2.65 \pm 0.18$ \\
\hline & & $p_{1}>0.05$ & & $p_{1}>0.05$ \\
\hline \multirow{2}{*}{ 3rd day of treatment } & $1.43 \pm 0.10$ & $1.95 \pm 0.13$ & $1.58 \pm 0.12$ & $2.13 \pm 0.16$ \\
\hline & $\mathrm{p}<0.001$ & $p>0.05 ; p_{1}<0.001$ & $\mathrm{p}<0.001$ & $p>0.05 ; p_{1}<0.05$ \\
\hline \multirow{2}{*}{ 7th day of treatment } & $0.68 \pm 0.12$ & $1.43 \pm 0.11$ & $0.96 \pm 0.13$ & $1.64 \pm 0.13$ \\
\hline & $\mathrm{p}<0.001$ & $p_{1} p_{1}<0.001$ & $p<0.001$ & $p<0.001 ; p_{1}<0.01$ \\
\hline \multirow{2}{*}{ 14th day of treatment } & $0.20 \pm 0.04$ & $1.39 \pm 0.08$ & $0.43 \pm 0.09$ & $1.37 \pm 0.12$ \\
\hline & $\mathrm{p}<0.001$ & $\mathrm{p}, \mathrm{p}_{1}<0.001$ & $p<0.001$ & $\mathrm{p}, \mathrm{p}_{1}<0.001$ \\
\hline
\end{tabular}

Note: $p$ - the significance of the difference between the index values before and during treatment (3rd, 7 th, 14 th day); $p_{1}-$ the significance of the difference between the indexes of the main and control groups.

intensity gingivitis is established. The decrease in OHI-S index values of $0.88 \pm 0.12$ scores $(\mathrm{p}<0.001)$ was noted, which corresponds to a satisfactory level of oral hygiene. In the examination of patients with hypertrophic gingivitis (Fig. 4), the disappearance of hypertrophy was noted only in $7 / 15$ (46.67 $\pm 12.88 \%)$ patients, slight gingivitis was diagnosed by PMA index (22.02 $\pm 2.18 \%)$, gum bleeding persisted (1.64 \pm 0.13 scores), the level of oral hygiene is satisfactory (0.94 \pm 0.13 scores).

Patients of the main group on the 14th day from the beginning of catarrhal gingivitis treatment noted a significant improvement in the gums appearance, the absence of soreness, bleeding, halitosis. As a result of the use of a diode laser, inflammatory phenomena in the periodontal tissues were absent, as indicated by a significant decrease in values of PMA index to $2.80 \pm 0.78 \%(\mathrm{p}<0.001)$. The gum mucosa has become a pale pink color, the edema of the gums and gingival papillae was gone. The bleeding index score was $0.20 \pm 0.04$. A significant improvement in the oral hygiene was observed: OHI-S index values were 0.43 \pm 0.13 scores and decreased 5 times $(p<0.001)$.

The patients of the main group with hypertrophic gingivitis did not complain on the 14th day from the beginning of periodontal treatment. The absence of hypertrophy, gin- gival pockets and bleeding was objectively noted, the gum mucosa acquired a pale pink color, no disease recurrence was observed. Only $3 / 15(20.0 \pm 10.33 \%)$ of the patients in this group had signs of slight inflammation in the form of insignificant hyperemia, the presence of inconspicuous edema of the gingival margin, a slight increase in the volume of the gums papillae, and the presence of spot bleeding during probing. Additional examination data: $\mathrm{OHI}-\mathrm{S}$ score of $0.53 \pm 0.12$, PMA $-5.80 \pm 1.78 \%\left(\mathrm{p}, \mathrm{p}_{1}<0.001\right)$, PBI score of $0.43 \pm 0.09\left(\mathrm{p}, \mathrm{p}_{1}<0.001\right)$.

In the control group on the 14th day from the beginning of drug treatment, patients did not observe any significant changes in relation to the 7 th day of observation, which was also confirmed by objective symptoms. The values of oral hygiene indexes, bleeding and gum inflammation have not changed significantly over the next seven days of observation.

\section{DISCUSSION}

Analyzing the results of clinical observations, it should be noted that the hygiene index, papillary-marginal-alveolar index and gum bleeding index were already decreased after the third visit. The use of laser radiation in the treat- 
ment of chronic catarrhal gingivitis contributed to the pain relief, decrease of bleeding and edema of the gums in $68.8 \%(11 / 16)$ patients on the 3rd day of observation, and the inflammatory process was completely eliminated on the 7 th day in $93.8 \%(15 / 16)$ of the examined patients. The combination of laser therapy with basic treatment of the edematous form of hypertrophic gingivitis has pronounced anti-inflammatory and decongestant effects. Confirmation of this has been the pain relief, absence of gingival bleeding and improvement of the gums aesthetic appearance in $33.3 \%(5 / 15)$ patients already at the 3rd session. $53.3 \%(8 / 15)$ of the examined patients have shown a positive dynamics of the stippling phenomenon at the 5 th session of laser therapy, in $80.0 \%(12 / 15)$ of the patients no hypertrophy, gingival pockets and gums bleeding has been observed on the 14th day of the examination.

Clinical observations which were carried out by us indicate the effectiveness of the diode laser use in the complex treatment of inflammatory periodontal diseases. Since, laser radiation blocks the inflammatory process, inhibits the pathogenicity of microorganisms, reduces the permeability of the vascular wall, improves the microcirculation, activates metabolic processes in the periodontal tissues, and promotes the regeneration and restoration of the gingiva $[6,9]$. The need for the use of steroidal anti-inflammatory drugs and antibacterial medicines is minimized or eliminated, which prevents the occurrence of unwanted side effects, including allergic reactions.

\section{CONCLUSIONS}

The efficiency of catarrhal gingivitis treatment was $93.8 \%$ in the main group and $68.8 \%$ in the control group, hypertrophic gingivitis treatment $-80.0 \%$ and $46.7 \%$, respectively. The results of the study indicate that laser therapy of chronic gingivitis in therapeutic efficacy exceeds conventional drug treatment, provides shortening in the term of complete elimination of the inflammatory process and suspends its further progression.

\section{REFERENCES}

1. Borysenko A.V., Lynovytska L.V., Nesyn 0.F. et al. Periodontal and Oral Mucosa Diseases: textbook. Kyiv: AUS Medicine Publishing. 2018; 2:624.

2. Michael G. Newman, Henry H. Takei, Femin A. Carranza. Garranza's clinical periodontology. USA, 2002; 9: 1033.

3. Nikolishyn A.K., Zhdan V.M., Borysenko A.V. ta in. Terapevtychna stomatolohiia: pidruchnyk u 2 t. [Therapeutic dentistry: textbook]. Poltava: Dyvosvit. 2007; 2: 280. (UA).

4. Demina K. Yu., Grishilova Ye. N., Kodzhakova T. Sh., Garaja S. Otsenka klinicheskikh rezultatov primeneniya fotodinamicheskoy i lazernoy terapii pri lechenii kataralnogo gingivita [Assessment of the clinical results of using the photodynamic and laser therapy in the treatment of catarrhal gingivitis]. Meditsinskiy vestnik Severnogo Kavkaza. 2016; 11(4):592-593. (Ru)
5. Euzebio Alves VT, de Andrade AK, Toaliar JM et al. Clinical and microbiological evaluation of high intensity diode laser adjutant to nonsurgical periodontal treatment: a 6-month clinical trial. Clin Oral Investig. 2013; 17(1):87-95.

6. Minić I. The Advantages of Laser in the Treatment of Gingivitis. Journal of Dentistry Forecast. 2019; 2(1):1-5.

7. Shinkaruk-Dikovitskaya M.M., Gadzhula N.G., Goray M.A., Kurdysh L.F. Povyshenie effektivnosti lecheniya khronicheskogo kataralnogo gingivita s primeneniem diodnogo lazera [Impovement of clinical effectiveness of chronic catarrhal gingivitis treatment with the use of diode laser]. Stomatologiya. Estetika. Innovatsii. 2017; 1(1):111-18. (UA).

8. Standarty nadannja medychnoji dopomoghy v Ukrajini. Medical care protocol:Shyfr MKKh K. 05.0 Ghinghivit kataraljnyj, Shyfr MKKh K. 05.01 Ghinghivit ghipertrofichnyj. [Standards of medical care in Ukraine. Medical care protocol: Code MKKh K. 05.0 Catarrhal gingivitis, Code MKKh K. 05.01 Hypertrophic gingivitis]. Available from: https://studfile. net. (UA).

9. Patrícia M. de Freitas, Alyne Simões. Lasers in Dentistry: Guide for Clinical Practice JohnWiley\&Sons, Inc. 2015;358.D0I:10.1002/9781118987742.

The work is a fragment of the research project "Modern trends and latest technologies in the diagnosis and treatment of odontopathology, diseases of periodontal tissues and oral mucous membrane", state registration No. 0118U005471. The article was not funded from external sources.

\section{ORCID and contributorship:}

Nataliia G. Gadzhula - 0000-0003-0016-2264 B,D

Mariia M. Shinkaruk-Dykovytska-0000-0002-0747-4247 ${ }^{C}$

Olena L. Cherepakha - 0000-0003-3629-4429 A

Maryna A. Goray - 0000-0003-4454-9161 ${ }^{F}$

Irina M. Horlenko - 0000-0001-8174-9651 ${ }^{E}$

\section{Conflict of interest:}

The Authors declare no conflict of interest.

\section{CORRESPONDING AUTHOR Nataliia G. Gadzhula \\ National Pirogov Memorial Medical University \\ 56 Pyrohov Str., Vinnytsia, Ukraine, 21018 \\ tel: +380977011918 \\ e-mail: natalidentist1@gmail.com}

Received: 20.01.2020

Accepted: 25.03 .2020

A - Work concept and design, B - Data collection and analysis, C - Responsibility for statistical analysis,

D-Writing the article, $\mathbf{E}$-Critical review, $\mathbf{F}$ - Final approval of the article 